\title{
Costs and benefits of carbon dioxide
}

THE release of carbon dioxide to the atmosphere by the burning of fossil fuels is, conceivably, the most important environmental issue in the world today. Whatever direction global energy policies take in the future, it is indisputable that carbon dioxide concentrations in the atmosphere will continue to rise. There is still uncertainty about the ultimate destination of carbon dioxide. It seems that roughly half the fossil fuel output has remained in the atmosphere, and early workers supposed that the remainder was consumed by the oceans and the biosphere. But the role of the biosphere is now a matter of hot debate. Some research has suggested that far from being a sink for carbon dioxide, the biosphere (through deforestation and changing land use) could actually be a source. Other work suggests the contrary, or that the role of the biosphere has actually changed with time. But it is inescapable that atmospheric concentrations have already climbed by $15 \%$ as a result of man's activities during this century and there seems little doubt that concentrations would be double present values around the middle of the next century if current growth rates for the use of fossil fuels (over $4 \%$ per annum) were to persist. This is unlikely, of course, given the depletion of energy resources, but at least the figure gives some sort of guide for realistic modelling.

Whatever the uncertainties about future emissions and the biosphere, there is no disagreement amongst researchers on the qualitative impact that an increase in carbon dioxide will have on climate: mean annual surface temperature will rise, and the rises will be greater at high latitudes. There is also consensus that the hydrological cycle would become more active-with precipitation and evaporation levels both rising. Beyond this there is still scope for quantitative disagreement, but a commonly quoted figure is that a doubling of atmospheric carbon dioxide would result in a world global annual mean surface temperature rise of 2 to $3{ }^{\circ} \mathrm{C}$, with marked latitudinal asymmetry. As yet, however, no model adequately accounts for changes in the ice-covered regions of the world or in the hydrosphere (particularly ocean currents), and there is considerable room for disagreement regarding the importance of feedback effects arising from changes in cloud cover.

With so much uncertainty around, is it irresponsible and premature to widen the debate at this stage from meteorologists and climatologists to those with interests in the consequences of climatic change-agriculturalists, glaciologists, oceanographers, economists, sociologists, political scientists and so on? Surely not, provided that sensible perspectives are maintained. A recent workshop jointly sponsored by the American Association for the Advancement of Science and the US Department of Energy has been attempting to lay transdisciplinary foundations for a federally supported research programme on the impact of increasing atmospheric carbon dioxide content and it is not too early for other nations (or more reasonably groups of nations, such as the European Economic Community) to take similar initiatives. Even if large amounts of money were not immediately forthcoming, there are still some links across the specialist boundaries which ought to be made now.

In the long run the United Nations presumably has to get in on the act, and the United Nations Environmental Programme will shortly be setting up a carbon dioxide committee. At first sight scientists might despair at the thought of yet another area in which there will be politicised conflict between industrialised nations, large-scale releasers of carbon dioxide, and the developing world, involuntary recipients of the consequences. But careful reading of what climatologists and meteorlogists have to say by way of prediction makes it clear that there could be as many benefits as losses as a result of temperature and rainfall changes-and that some parts of the world may even become cooler.

There is no clear indication that the animal and plant kingdoms will as a whole prosper more or less in a changed climate. And there may be direct carbon dioxide effects, such as changes in the rates of photosynthesis and respiration, increases in the efficiency of plant water use and changes in nitrogen fixation rates. To be sure, the most widely publicised effect of a substantial global warming is the danger of the West Antarctic Ice Sheet breaking loose and melting, with highly predictable effects on sea level. But for the rest the picture is complex and by no means universally gloomy. The sooner some of the complexities are unravelled, the sooner the carbon dioxide problem can be intelligently injected into discussions of world energy strategies. 